\title{
Effect of Embrittlement on the Microstructure, Mechanical and Wear Properties of Aged Super Duplex Stainless Steel
}

\author{
Mahesh Davanageri ${ }^{1}$, D. Disha ${ }^{1}$ and K. Raju, ${ }^{2, *}$ \\ ${ }^{1}$ Department of Mechanical Engineering, SCEM, Mangaluru - 575007, India \\ ${ }^{2}$ Department of Mechanical Engineering, SJEC, Mangaluru - 575028, India
}

\begin{abstract}
In the present study, the effect of embrittlement on the microstructural features, mechanical and dry sliding wear properties of AISI 2507 super duplex stainless steel (SDSS) has been discussed. Prior to heat treatment the SDSS has been solution treated. Further, SDSS has been heat treated at $475^{\circ} \mathrm{C}$ for $60 \mathrm{~min}$ and then quenched in water and oil at room temperature. The heat treatment has led to the embrittlement in SDSS owing to the decomposition of ferrite phase by spinodal decomposition into two phases, Cr-rich $\left(\alpha^{\prime}\right)$ phase and Fe-rich $(\alpha)$ phase. Embrittlement of super duplex stainless steel resulted in significant improvement in ultimate tensile strength and hardness. However, a decrease in the impact energy has been observed. Oil quenched super duplex steel has better wear resistance compared to water quenched and solution treated steels.
\end{abstract}

Keywords: Embrittlement, Microstructure, Hardness, Tensile strength, Heat treatment, Wear.

\section{INTRODUCTION}

In recent years, the widespread use of duplex stainless steels in pulp and paper, offshore oil, gas, chemical, petroleum and power industries increased due to their good mechanical properties and excellent corrosion resistance [1-3]. Duplex stainless steels (DSS) are assemblage of two phase microstructure of ferrite and austenite. The approximately two equal phase microstructure of ferrite and austenite combines the effects of the two phases that are beneficial to make the DSS to obtain high strength of ferrite and toughness of austenite $[4,5]$.

The embrittlement occurs in the temperature range of $280-500^{\circ} \mathrm{C}$ due to solid state reaction within ferrite phase and it has been extensively reported in the literature that the embrittlement rate is highest at $475^{\circ} \mathrm{C}$. It has been observed that the embrittlement alter the mechanical properties significantly and it limits the usage of duplex stainless steel below the temperature of $280^{\circ} \mathrm{C}$ [6-8]. Embrittlement results in decomposition of highly alloyed ferritic phase into iron rich phase $(\alpha)$ and chromium rich phase $\left(\alpha^{\prime}\right)$ and it was also noticed that ferrite is unstable within the miscibility gap and therefore, ferrite decomposes into two phases. Embrittlement concept is normally ascribed to the spinodal decay of the ferrite, to be specific, the development of ferrite-advanced ( $\alpha$ ) stage and chromium-enhanced $\left(\alpha^{\prime}\right)$ stage, or the arrangement of

\footnotetext{
*Address correspondence to this author at the Department of Mechanical Engineering, SJEC, Mangaluru - 575028, India; Tel: +91-8123798293;

E-mail: rajuksjec@gmail.com
}

chromium-improved $\left(\alpha^{\prime}\right)$ expedites installed in a ferriterich $(\alpha)$ lattice in the wake of maturing in the temperature range from 250 to $550^{\circ} \mathrm{C}$ [9]. The embrittlement at $475^{\circ} \mathrm{C}$ significantly affects the properties like hardness, impact, tensile strength and toughness. However, very few researchers have focused on the effects of heat treatment carried out at low temperatures on mechanical and wear behavior of duplex stainless steel. The present study is mainly focused on exploring the possibilities to enhance the wear properties of aged AISI 2507 super duplex stainless steel, which finds wide application in pumps, valves and bearings.

\section{MATERIALS AND METHODS}

\subsection{Chemical Composition of AISI 2507 Super Duplex Stainless Steel}

The commercially available as-cast AISI 2507 SDSS was selected for the present study. The chemical composition of the material (solution treated at $1050^{\circ} \mathrm{C}$ for $120 \mathrm{~min}$ ) obtained by emission arc spectrometer has been presented in Table 1.

\subsection{Mechanical Testing of AISI 2507 SDSS}

The ultimate tensile strength (UTS) and yield strength (YS) were determined by tensile testing. Room temperature experiments were conducted using computer controlled TINIUS OLSEN H75KS (Tinius Olsen, UK) Universal Testing Machine (Figure 1(a)). Specimen having a gauge length of $25 \mathrm{~mm}$ was processed as per ASTM E8 standard (Figure 1(b) \& (c)). The yield and tensile strengths of the heat treated 
Table 1: Chemical Composition Weight (\%) of Solution Treated AISI 2507 SDSS

\begin{tabular}{|c|c|c|c|c|c|c|}
\hline C & Cr & Ni & Mo & Mn & Si & N \\
\hline \hline 0.019 & 25.387 & 6.714 & 3.77 & 0.738 & 0.328 \\
\hline
\end{tabular}

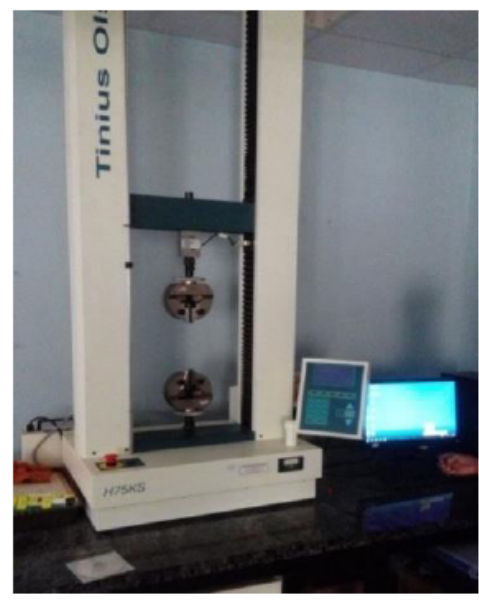

(a)

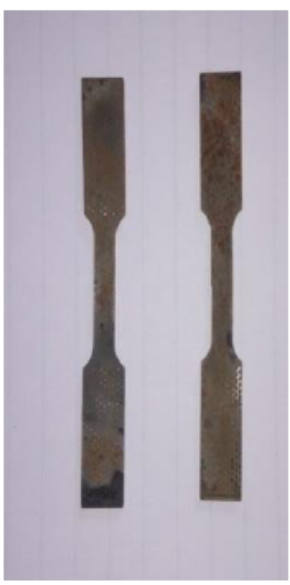

(b)

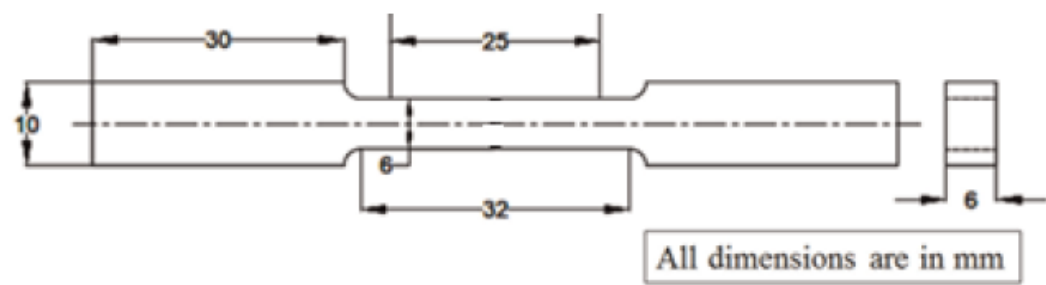

(c)

Figure 1: (a) Universal Testing Machine (b) Prepared tensile specimens (c) Specimen dimensions as per ASTM E8.

specimens were evaluated and the average value of three readings was taken.

The Charpy impact test was carried out as per ASTM E23 standard to measure the fracture toughness. The impact testing was performed on the specimens of size $55 \times 10 \times 5 \mathrm{~mm}$ with $\mathrm{V}$-notch.

The Rockwell hardness tester with a cone indenter of $120^{\circ}$ was used to determine the hardness. The applied load was $150 \mathrm{kgf}$. Five trials have been conducted and the average value has been reported.

\subsection{Wear Testing}

The wear test samples of size $\varnothing 10 \times 30 \mathrm{~mm}$ were prepared as per ASTM G99A [10]. The specimens were then subjected to heat treatment at $1050^{\circ} \mathrm{C}$ for $120 \mathrm{~min}$. Further, they were quenched in water to obtain the balanced two phase microstructure of ferrite and austenite. Subsequently specimens were further heat treated at $475^{\circ} \mathrm{C}$ for 60 min and then quenched in water as well as in oil. Dry sliding wear tests were conducted on pin-on-disc wear test rig (Model: TR-20, DUCOM) as per ASTM G99A. The samples were properly cleaned with acetone before testing. The wear test process parameters are as shown in Table 2.

\subsection{Metallography}

The specimens for microscopic study were prepared using standard metallographic techniques $[10,11]$. Microstructure analysis was carried out on the heat treated specimens using scanning electron microscope.

\subsection{Solution Heat Treatment}

The solution heat treatment was carried out in the temperature range of $1000-1400^{\circ} \mathrm{C}$. The specimens prepared for experimentation work were initially subjected to solution treatment at $1050^{\circ} \mathrm{C}$ for $120 \mathrm{~min}$ 
Table 2: Wear Test Process Parameters

\begin{tabular}{|c|c|c|c|c|c|c|}
\hline S. No. & Operating Conditions & & & & & \\
\hline 1 & Load $(\mathrm{kg})$ & 1 & 2 & 3 & 4 & 5 \\
\hline 2 & Velocity (m/s) & 1 & 2 & 3 & 4 & 5 \\
\hline 3 & Distance (m) & 200 & 400 & 600 & 800 & 1000 \\
\hline 4 & Relative humidity & \multicolumn{5}{|c|}{$70 \%$} \\
\hline 5 & Track diameter $(\mathrm{mm})$ & \multicolumn{5}{|c|}{140} \\
\hline 6 & Temperature & \multicolumn{5}{|c|}{ Room temperature } \\
\hline 7 & Surface condition & \multicolumn{5}{|c|}{ Dry } \\
\hline
\end{tabular}

and then quenched in water at room temperature. The solution treated specimens were further exposed to a temperature of $475^{\circ} \mathrm{C}$ for $60 \mathrm{~min}$ and subsequently quenched in water and oil.

\section{RESULTS AND DISCUSSION}

\subsection{Microstructural Features}

The optical and SEM micrographs of solution treated super duplex steel were shown in Figure 2(a)

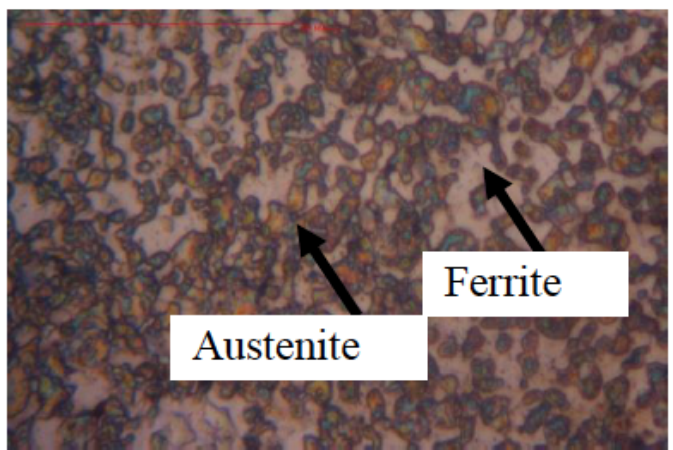

(a) and (b). It was observed that only two phases were present and there was no evidence for the existence of other phases. Further, to confirm the phase present in the microstructure the XRD analysis of solution treated steel was carried out and only two peaks of austenite and ferrite were observed as shown in Figure 3(a). The volume fraction of austenite and ferrite phase in the microstructure was determined based on the measured area of each phase with the help of optical image analyser. The optical micrograph of solution treated (as-cast) steel was shown in Figure 3(b). The individual

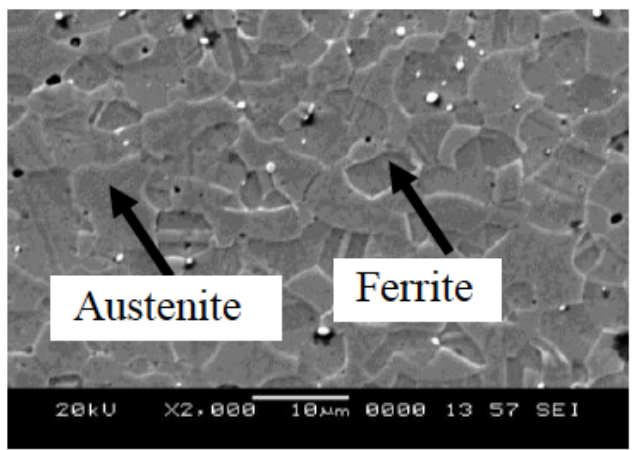

(b)

Figure 2: Micrographs of solution treated AISI 2507 SDSS (a) Optical \& (b) SEM.

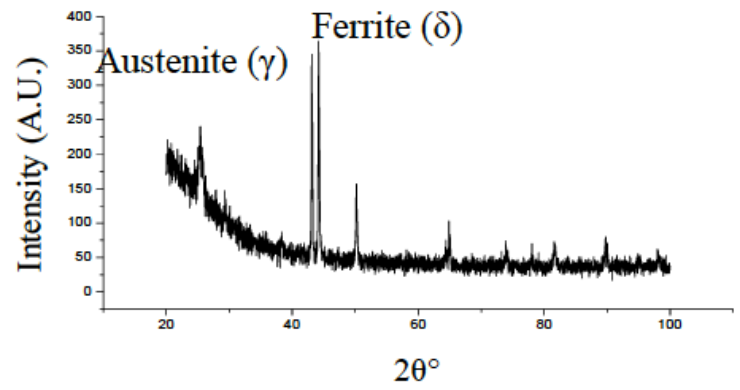

(a)

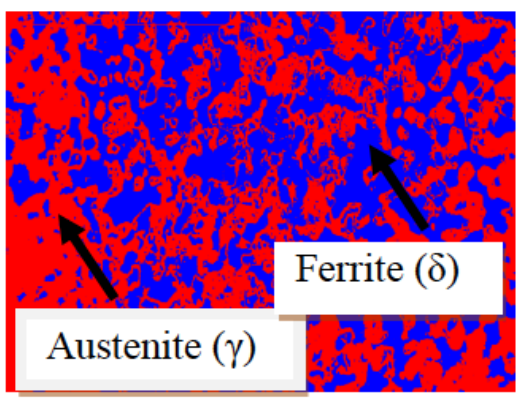

(b)

Figure 3: (a) XRD pattern (b) Volume fractions of austenite \& ferrite in super duplex steel. 


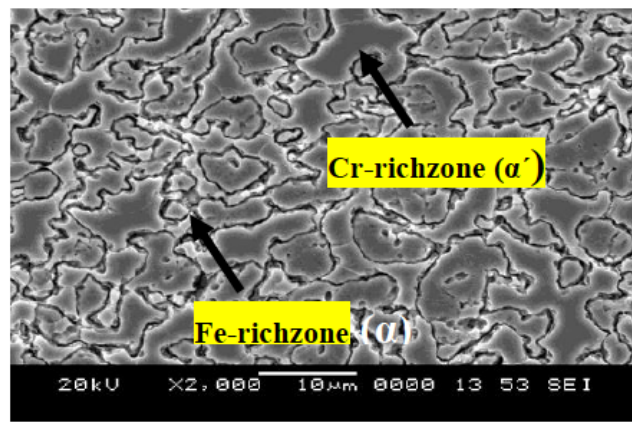

(a)

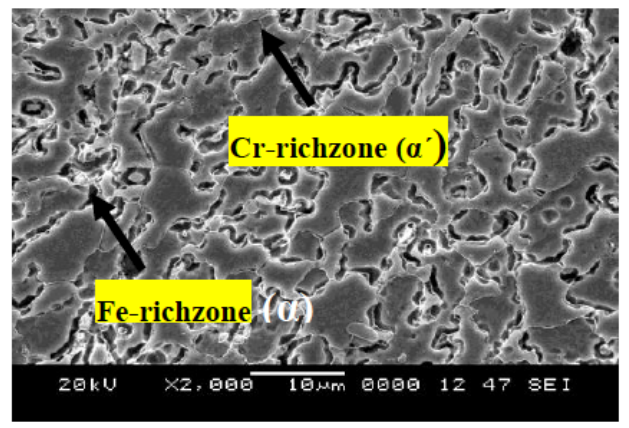

(b)

Figure 4: Micrographs of heat treated super duplex steel (a) water quenched (b) oil quenched.

Table 3: Tensile Properties of Super Duplex Stainless Steel at $475^{\circ} \mathrm{C}$

\begin{tabular}{|c|c|c|c|}
\hline Stress (MPa) & $\begin{array}{l}\text { Solution Heat Treated at } 1050^{\circ} \mathrm{C} \\
\text { for } 120 \mathrm{~min}\end{array}$ & $\begin{array}{c}\text { Heat Treated at } 475^{\circ} \mathrm{C} \text { for } 60 \mathrm{Min} \text { and } \\
\text { Water Quenched }\end{array}$ & $\begin{array}{c}\text { Heat Treated at } 475^{\circ} \mathrm{C} \text { for } 60 \mathrm{Min} \\
\text { and Oil Quenched }\end{array}$ \\
\hline Yield stress & 554 & 815 & 915 \\
\hline Ultimate stress & 804 & 919 & 970 \\
\hline
\end{tabular}

phases were shown with different colours in the micrograph. The volume fraction of austenite and ferrite in the solution treated specimen was found and average volume fraction was observed to be $55 \%$ for the ferrite and $45 \%$ for austenite.

The microstructures of heat treated and water and oil quenched specimens were shown in Figure 4(a) \& (b). The embrittlement at $475^{\circ} \mathrm{C}$ has led to the formation of ferrite-enriched ( $\alpha$ ) phase and chromiumenriched $\left(\alpha^{\prime}\right)$ phase, or the formation of chromiumenriched $\left(\alpha^{\prime}\right)$ precipitates embedded in a ferrite-rich $(\alpha)$ matrix in the microstructure. These features are in line with the findings of Villanueva et al. and Mayasuki et al. $[12,13]$. The microstructures were observed to be mottled and contrast in nature as seen in Figure 4(a) \& (b). This type of contrast will be observed in the spinodally decomposed materials and the darkish gray regions represent the $\mathrm{Cr}$-rich zone, while dim gray regions represent the Fe-rich zone. These mottled regions were observed to be more in oil quenched compared to water quenched super duplex steel [5].

\subsection{Tensile Properties}

The results of tensile testing were presented in Table 3. It was observed that there was an increase in ultimate tensile strength and yield strength in both water and oil quenched super duplex steel. It is mainly due to the embrittlement occurred during the heat treatment. The spinodal decomposition can obstruct the dislocation movement and affects the plasticity which leads to an increase in the yield and ultimate strengths of the heat treated steel. However, yield and ultimate stresses were observed to be maximum in the oil quenched compared to water quenched and solution treated super duplex steel. This is mainly due to high embrittlement rate in oil quenched super duplex steel $[6,8]$.

\subsection{Hardness}

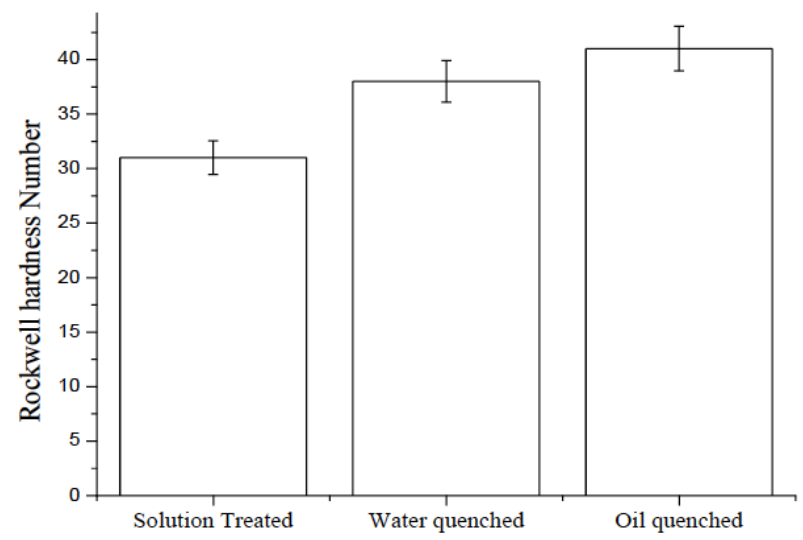

Figure 5: Rockwell hardness of super duplex steel.

The Figure 5 depicts the hardness of AISI 2507 super duplex steel. A noticeable increase in the hardness was observed in the super duplex steel specimens that were heat treated, quenched in oil and water. The heat treated specimens show better hardness compared to solution treated due to formation of hard phases of chromium-enriched $\left(\alpha^{\prime}\right)$ precipitates 
embedded in a ferrite-rich ( $\alpha$ ) matrix after aging due to spinodal decomposition of ferrite phase as seen in the Figure 4(a) \& (b) which promote the hardening of the heat treated steel specimens $[6,7,10]$.

\subsection{Impact Energy}

The Figure 6 depicts the graph of impact energy versus ageing time. It was observed that there is a significant reduction in the impact energy in both water and oil quenched steel specimens. The impact energy drops to $80 \mathrm{~J}$ in water quenched and $65 \mathrm{~J}$ in oil quenched steel specimens when compared to solution treated steel specimen having an impact energy of 260 $\mathrm{J}$. The decrease in the impact energy of duplex stainless steel is mainly due to dislocation pinning caused by chromium, carbon and nitrogen atoms which are due to spinodal decomposition occurred during the heat treatment. Spinodal decomposition can slow down the dislocation movement and further it stops the dislocation movement and leads to plasticity in turn increasing the yield strength which is associated (Table 3) with decrease in toughness [3, 9].

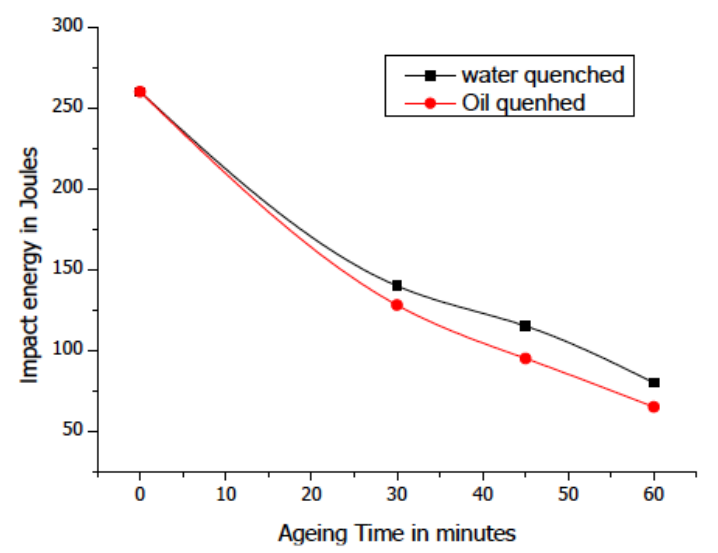

Figure 6: Variation of impact energy with ageing time at $475^{\circ} \mathrm{C}$.

\subsection{Wear Behaviour}

\subsubsection{Effect of Load}

The material loss because of wear due to application of load on heat and solution treated specimens were shown in Figure 7(a). The load was varied in the range of 1 to $5 \mathrm{~kg}$. Results have revealed that the wear behaviour has been impacted due to applied load. Wear volume loss increased with increase in load and also increased in solution treated as well as in heat treated specimens for the entire range of applied load. However, it has been observed that there was a significant improvement in the wear resistance of heat treated specimens quenched in water and oil. Further, in particular the oil quenched specimens show better wear resistance compared to solution treated and heat treated with water quenched specimens due to an increase in the hardness during embrittlement. It was noticed that, as the load increased temperature at the interface of two rubbing surfaces due to friction also increased, which resulted in formation of debris, thermal softening and oxidation of debris and caused enhancement of wear volume loss in solution treated specimens. The improvement in the wear resistance of heat treated specimens was mainly due to the formation of two phases, Cr-rich and Fe-rich phases because of embrittlement occurred during the heat treatment. Further enhancement in the hardness of heat treated specimens due to formation of these phases has significantly improved the wear resistance in the heat treated specimens $[4,10]$.

\subsubsection{Effect of Sliding Velocity}

The Figure $\mathbf{7 ( b )}$ shows wear loss with sliding velocity. The wear volume loss increased with increase in the sliding velocity. However, it was observed that beyond $4 \mathrm{~m} / \mathrm{s}$ velocity the wear loss decreased in all the specimens. This is mainly due to the transition
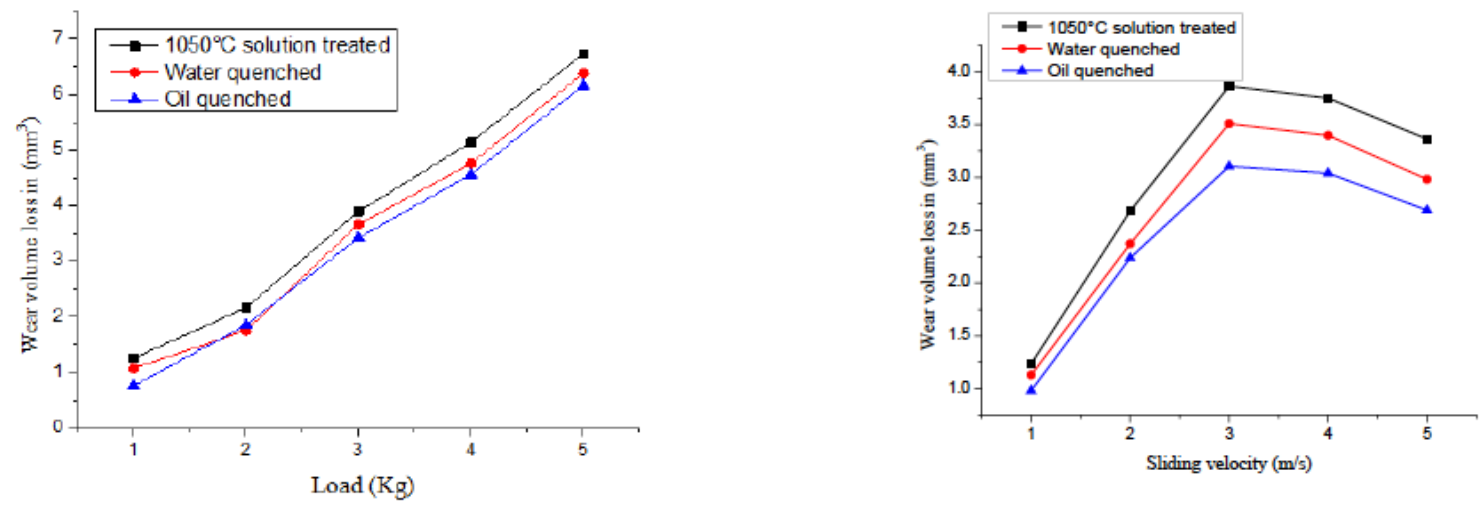

Figure 7: Variation of (a) wear loss vs load (b) wear loss vs sliding velocity. 
period during which the frictional force reduces as sliding velocity increases. The transition velocity will depend on material structure and there is a distinct transition velocity for each structure above which its wear loss starts decreasing as observed in the Figure 7(b). Further, the profundity of plastic disfigurement may increment and structures the tribological layer and this layer has been observed more beyond $4 \mathrm{~m} / \mathrm{s}$, accordingly separating the normal thickness of the debris. This diminishes the measure of entangled debris, which is to be oxidized, accordingly prompting the progress $[4,11]$.

\section{CONCLUSIONS}

The following conclusions may be drawn from the present study:

- $\quad$ The annealed and quenched (water \& oil) super duplex stainless steel resulted in balanced microstructure consisting of ferrite and austenite phases approximately in equal proportion.

- The ultimate tensile strength and hardness have been improved by 13 \& $18 \%$ in heat treated and water quenched and $17 \& 24 \%$ in heat treated and oil quenched steel respectively compared to solution treated super duplex steel.

- The impact energy has been decreased as the ageing time increased for heat treated and quenched (water and oil) super duplex steel compared to the solution treated super duplex stainless steel.

- $\quad$ The heat treated and oil quenched super duplex steel has shown better wear performance compared to solution treated and heat treated and water quenched super duplex steel.

\section{REFERENCES}

[1] Olsson J and Snis M, Duplex - a new generation of stainless steels for desalination plants, Desalination 2007; 205(1-3): 104.

https://doi.org/10.1016/j.desal.2006.02.051
[2] Lasebikan BA, Akisanya AR and Deans WF, The mechanical behaviour of a $25 \mathrm{Cr}$ Super duplex stainless steel at elevated temperature, Journal of Materials Engineering and Performance 2013; 22(2): 598.

https://doi.org/10.1007/s11665-012-0273-5

[3] Vogt JB, Massol $\mathrm{K}$ and Foct J, Role of microstructure on fatigue properties of $475^{\circ} \mathrm{C}$ aged duplex stainless steels, International Journal of Fatigue 2002; 24: 627. https://doi.org/10.1016/S0142-1123(01)00187-6

[4] Fargas G, Mestra A, Mateo A, Effect of sigma phase on wear behavior of a super duplex stainless steel, Wear 2013; 303(1-2): 584. https://doi.org/10.1016/j.wear.2013.04.010

[5] Weng $\mathrm{KL}$ and Chen $\mathrm{HR}$, The low temperature aging embrittlement in a 2205 duplex stainless steel, Material Science and Engineering 2004; 379: 119. https://doi.org/10.1016/j.msea.2003.12.051

[6] Sahu JK, Krupp U, Ghosh RN, Christ HJ, Effect of $475^{\circ} \mathrm{C}$ embrittlement on the mechanical properties of duplex stainless steel, Materials Science and Engineering 2009; 508: 168.

https://doi.org/10.1016/j.msea.2009.01.039

[7] Hanninen H, Romu J, llola R, Tervo J, Laitinen A, Effects of processing manufacturing of high nitrogen-containing stainless steels on their mechanical, corrosion and wear properties, Journal of Material Processing and Technology 2001; 117: 424 https://doi.org/10.1016/S0924-0136(01)00804-4

[8] Martins $M$, and Castelleti LC, Effect of heat treatment on mechanical properties of ASTM A890 Gr6A super duplex stainless steel, Journal of ASTM International 2005; 2: 1. https://doi.org/10.1520/JAI13037

[9] Hwang TH, Kim JH, Kim KH, Moon WJ, Kang CY, Effect of R-phase on impact toughness of $25 \mathrm{Cr}-7 \mathrm{Ni}-4 \mathrm{Mo}$ super duplex stainless steel, Metals and Materials International 2014; 20 : 13.

https://doi.org/10.1007/s12540-014-1004-2

[10] Davanageri $M$, Narendranath $S$ and Kadoli R, Influence of ageing time on hardness, microstructure and wear behaviour of AISI2507 super duplex stainless steel, Materials Research Express 2017; 4(8): 086506 https://doi.org/10.1088/2053-1591/aa80a1

[11] Davanageri $M$, Narendranath $S$ and Kadoli R, Dry sliding wear behavior of super duplex stainless steel AISI 2507: A statistical approach, Archives of Foundry Engineering 2016; 16(4): 47. https://doi.org/10.1515/afe-2016-0082

[12] Villanueva DME, Junior FCP, Ronald L and Padilha AF, Comparative study on sigma phase precipitation of three types of stainless steels: austenitic, super ferritic and duplex, Materials Science Technology 2006; 22: 1098.

\section{https://doi.org/10.1179/174328406X109230}

[13] Masayuki A, Toshifumi $\mathrm{K}$ and Yoshihiko $U$, Microstructural changes of chromium ferritic stainless steel subjected to cyclic loading in $475{ }^{\circ} \mathrm{C}$ Embrittlement region, Procedia Engineering 2011; 10: 100 . https://doi.org/10.1016/j.proeng.2011.04.019 